\title{
Bridging the Gap Between Tool Path Generation for Sculptured Surface Machining and Computer Aided Process Modelling Techniques
}

\author{
Gadalla, Mohamed A. E. (GADALLA@FRCU.EUN.EG) \\ Cairo University, Fac. of Engrg., Prod. Dept., Egypt \\ ElMaraghy, Waguih H. (wem@ims.uwindsor.ca) \\ Intelligent Manufacturing Centre, University of Windsor
}

Key words: $\quad$ CAD/CAM, Sculptured-surface machining, Cutting Force

Abstract: $\quad$ Tool path generation for sculptured surface machining and computer aided process modelling has been an active area of research for the past few decades. The next development stage is to integrate the two research themes to improve the final product quality. This paper gives some insight into the anticipated difficulties and the problems which must be solved in order to achieve this goal. The research was conducted based on a case study in which the geometric modeller for sculptured surfaces and the system of cutting force calculations were integrated. One merit gained is that the tool deflection was predicted and compensated for during the tool path generation phase. As a result, a more accurate machined surface was obtained.

\section{INTRODUCTION}

In curved surface machining, parametric surface representation is normally used for the computer-aided design (CAD) portion. Parametric surfaces are often machined using an end mill for roughing and a ball mill for finishing. There are two main approaches to generate the cutter location file required for tool path generation for these surfaces. The first approach depends on generating the cutter contact point on the surface to be machined followed by an offsetting operation to generate the cutter location point to be used by the machine tool controller in driving the cutter along the programmed path. The second approach is based on generating the offset surface that represents the loci of the cutter location points. The first approach is widely used in commercial CAD/CAM systems [13].

The next development stage is to enhance the phase of tool path generation by adding intelligent tools to either produce machined parts faster and/or more accurately. Some of the research work that has been performed in this direction has focused on the automatic generation of the feed rate (Hemmett et a. [17], Lim [15], and Fussell et. al. [2, 16]). The idea is based on maintaining a constant magnitude for the cutting force. The cutting force can be chosen so that it does not violate certain constraints, such as the maximum holding force or maximum torque etc. [17].

In the second approach it is required to accurately model the resultant error during the cutting process and design error compensation schema. The error due to the tool deflection is one of the well known source of errors that can be determined and avoided.

The work reported by Fussell et al. [16] has combined an inverse mechanistic model with the geometric model based on the surface point set (SPS). This is used to compute the feed rate that maximizes the metal removal rate in the case of roughing, and maintaining certain levels of the cutting force in the case of finishing.

The original version of this chapter was revised: The copyright line was incorrect. This has been corrected. The Erratum to this chapter is available at DOI: 10.1007/978-0-387-35392-0_40 
ElMounayri et al. [14] proposed an enhancement to the CAD/CAM systems by using a conventional system with a machining process simulator and a coordinate measuring machine (CMM). The machining process simulator is based on a generic geometric modelling approach which combines solid, surface and curve modelling to accurately represent the different geometric entities involved in the process. The physical model is composed of force models that accurately predict the process parameters. The coordinate measuring machine is intended to accurately model the cutting edge in order to fit a B-spline curve to the measured points so that any cutting tool shape can be used.

In this paper prediction of the deflection of the cutting tool (based on modelling the cutting force) at certain points distributed on the design surfaces is calculated. A geometric modeller based on the variable offset technique developed by the authors $[8,13]$ was used to generate the compensated surface model. The compensated surface model is used to generate the cutter location points rather than the design surface.

\section{MODELLING OF THE CUTTING FORCE}

Smith and Tlusty in their paper [4] classified the modelling of the cutting force into five levels depending on accuracy and sophistication. The first level is the average rigid force and static deflection. The cutting force is calculated from the first principles of metal cutting. The cutting power is calculated as the multiplication of the specific cutting energy by the rate of metal removal, hence the cutting force can be calculated. The disadvantages of this technique are that the direction of the cutting force is not known [2], and the size effect is not taken into consideration. The second level is the instantaneous rigid force. In this model the cutting force is calculated as a multiplication of the undeformed chip area by a certain constant. The third level is the instantaneous rigid force, static deflection model in which deflection is calculated as a profile error where a surface generation point is determined and the direction and magnitude of the deflection are computed based on beam theory. Kline [5] developed a version of this model in which he sliced the end mill tool into thin discs and calculated the incremental cutting force for each disc. He referred to this as the incremental cutting force model. The fourth level is the instantaneous force with static deflection feedback, whereby the effect of tool deflection is considered in the calculation of the undeformed chip thickness. The last level is the regenerative force, dynamic deflection model. In this model the inertial forces within of the system (tool, workpiece, spindle) are considered, in addition to the effect of the topology of the surface left by the passage of the previous cutting tooth on the already engaged tooth [6].

\subsection{Incremental Cutting Force For and End Mill}

The incremental mechanistic model by Kline [5] has been taken as the basis for developing the cutting force model for this work. As previously mentioned in the introduction, the cutting force is calculated over a thin disc of the cutting tool, where the varying parameters due to change of helix angle are assumed constant. For each disc the chip load is determined, followed by the calculation and distribution of the cutting force as a function of the rotational angle. As shown in Fig. 1, the total cutting force can be expressed as a summation of the elemental radial and tangential components from equations 1 and 2 .

$$
\mathrm{F}_{\mathrm{tn}}=\mathrm{K}_{\mathrm{t}} \mathrm{D}_{\mathrm{z}} \mathrm{t}_{\mathrm{c}} \quad \text { (1) } \quad \mathrm{F}_{\mathrm{rl}}=\mathrm{K}_{\mathrm{r}} \mathrm{F}_{\mathrm{tn}}
$$

Where, $F_{t n}$ is the elemental tangential force, $F_{r l}$ is the elemental radial force, $D_{z}$ is the force element width, $t_{c}$ is the chip load, and $\mathrm{K}_{\mathrm{t}}, \mathrm{K}_{\mathrm{r}}$ are empirical constants. In order to calculate the chip angle $\beta$, the angular spacing angle $\gamma$, and the angular increments of the cutter rotation $\theta$, 
are calculated from equations 3 and 4.

$$
\begin{aligned}
& \gamma=\left(\frac{2 \Pi}{N_{f}}\right) \\
& \theta(j)=J\left(\frac{\Pi}{N_{\theta}}\right) \quad\left(j=1,2, \ldots \ldots N_{\theta}\right)
\end{aligned}
$$

Where, $N_{f}$ is the number of flutes and $N_{\theta}$ is the number of the angular increments of the cutter rotation. Indicating the parameter $i$ as the ith axial disc element, $j$ as the jth angular position of the cutter, and $\mathrm{k}$ as the kth flute number. The chip thickness is calculated as a function of the chip angle $\beta$ according to equation 5 .

$$
\begin{aligned}
& \mathrm{t}_{\mathrm{c}} \approx \mathrm{f}_{\mathrm{t}} \sin \beta(\mathrm{i}, \mathrm{j}, \mathrm{k}) \\
& \text { Where } \beta(\mathrm{i}, \mathrm{j}, \mathrm{k}) \text { is calculated from equation } 6 . \\
& \beta(\mathrm{i}, \mathrm{j}, \mathrm{k})=[-\theta(\mathrm{j})+(\mathrm{k}-1) \gamma]+\left((\mathrm{i}-1) \mathrm{D}_{\mathrm{z}}+\frac{\mathrm{D}_{\mathrm{z}}}{2}\right) \\
& \tan \left(\alpha_{\mathrm{hx}}\right) /(\mathrm{R}), \alpha_{\mathrm{ex}} \leq \beta(\mathrm{i}, \mathrm{j}, \mathrm{k}) \geq \alpha_{\mathrm{en}}
\end{aligned}
$$

Where $\alpha_{\mathrm{hx}}$ is the helix angle, $\alpha_{\mathrm{ex}}$ is the exit angle, $\alpha_{\mathrm{en}}$ is the entry angle and $\mathrm{R}$ is the tool radius. It should be noted that the middle term is due to the fact that the surface generation process is viewed as the projection of a helical tooth sliding across the work surface [7]. In order to calculate the $\mathrm{X}$ and $\mathrm{Y}$ components, the elemental tangential and radial forces are resolved into $\mathrm{X}$ and $\mathrm{Y}$ coordinates according to equations 7 and 8 .
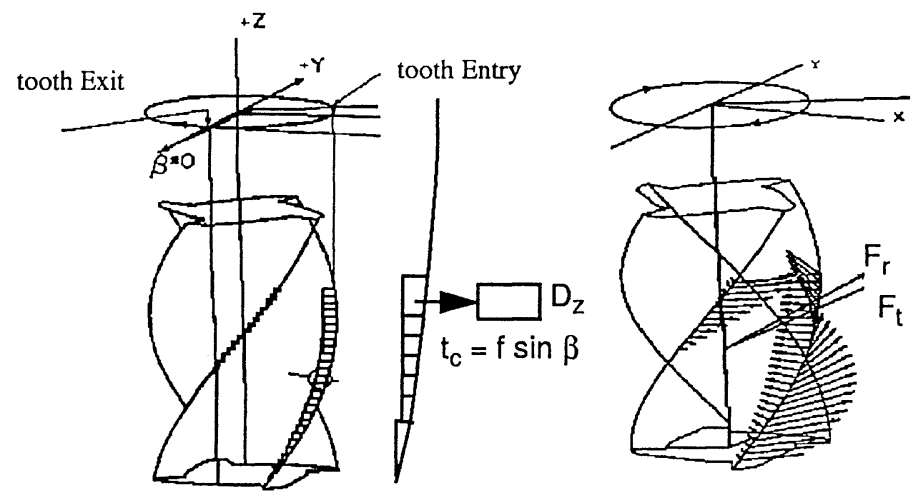

Fig. 1 The Cutting Force for an End Mill

The total $\mathrm{X}$ and $\mathrm{Y}$ force components at the jth angular position are obtained by summing the above two elemental forces, as given in equations 9 and 10 .

$$
\begin{aligned}
D F_{x} & =\sum_{i=1}^{{ }_{i} v_{f}}-D F_{r} \times \sin \beta(i, j, k)+D F_{t} \times \cos \beta(i, j, k) \\
D F_{y} & =\sum_{i=1}^{N_{f}} D F_{r} \times \cos \beta(i, j, k)+D F_{t} \times \sin \beta(i, j, k)
\end{aligned}
$$




$$
\mathrm{F}_{x}=\sum_{\mathrm{i}=1}^{\mathrm{N}_{\mathrm{z}}} \mathrm{DF}_{\mathrm{x}} \quad \text { (9) } \quad \mathrm{F}_{y}=\sum_{\mathrm{i}=1}^{\mathrm{N}_{\mathrm{z}}} \mathrm{DF}_{\mathrm{y}}
$$

\subsection{Calculation of the Entry and Exit Angles}

The entry and exit angles shown in Fig. 2 represent the limits between which the chip angle $\beta$ must lie. Mathematically, they represent the integration limits[5]. Calculation of theses angles involves identifying whether the dominant process is up or down milling. For down milling (group 1) the exit angle is zero, and the entry angle is calculated from the process parameters (axial depth of cut and tool radius). For up milling (group 2) they are reversed.

\subsection{Determination of The Number of Engaged Flutes During one Complete Revolution}

As shown in Fig. 3, flute number 1 will be engaged in the cutting process twice during one complete revolution due to the helix action. To preserve the integrity of the model, the calculation of the chip angle should be different for each case. Modification was suggested for calculating the chip angle $\beta$ using equations 11 and 12 for group 1, and equations 13 and 14 for group 2. The first equation in each group is used if the flute is engaged for the first time, while the second equation applies if it is engaged for the second time.

\subsection{Extending the Cutting Force Model}

The previous cutting force model was developed originally for down milling, where the cutting feed direction is in the $\mathrm{x}+$ direction with a maximum depth of cut off less than or equal to the tool radius. Since this is not always the case during the machining of sculptured surfaces, there is a need to extend the model to include more cases. Eight cases were identified for extending the cutting force model [8]. These depend upon whether the feed vector is in the $+x$ or $-x$ direction, the infeed vector (cross feed) is in the $+y$ or $-y$ and vice versa, and whether the dominant milling operation is up or down milling.

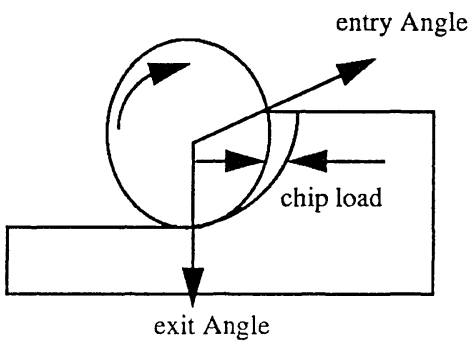

Fig. 2 The Entry and Exit Angles

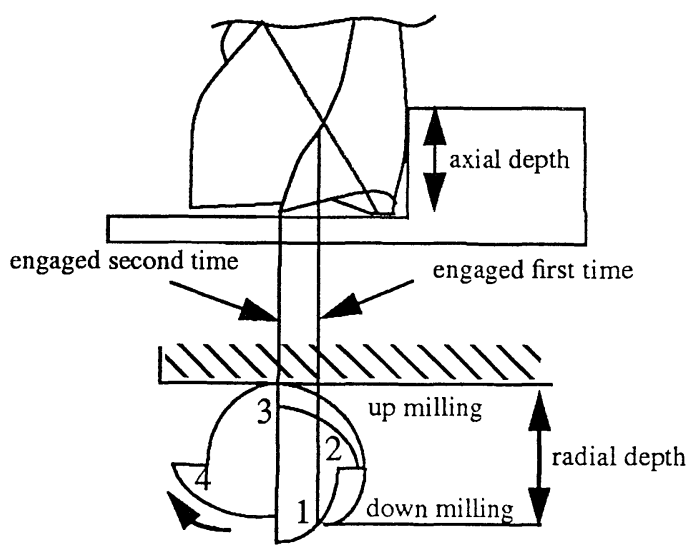

Fig. 3 Number of Flutes Engaged 


$$
\begin{aligned}
& \text { Group } 1 \\
& \beta(\mathrm{i}, \mathrm{j}, \mathrm{k})=-\theta(\mathrm{j})+(\mathrm{k}-1) \gamma+\left((\mathrm{i}-1) \mathrm{D}_{\mathrm{z}}+\frac{\mathrm{D}_{\mathrm{z}}}{2}\right) \times \tan \left(\alpha_{\mathrm{hx}}\right) /(\mathrm{R}) \\
& \beta(\mathrm{i}, \mathrm{j}, \mathrm{k})=2 \times \pi-\theta(\mathrm{j})+(\mathrm{k}-1) \gamma+\left((\mathrm{i}-1) \mathrm{D}_{\mathrm{z}}+\frac{\mathrm{D}_{\mathrm{z}}}{2}\right) \times \tan \left(\alpha_{\mathrm{hx}}\right) /(\mathrm{R}) \\
& \quad \text { Group } 2 \\
& \beta(\mathrm{i}, \mathrm{j}, \mathrm{k})=\theta(\mathrm{j})-(\mathrm{k}-1) \gamma-\left((\mathrm{i}-1) \mathrm{D}_{\mathrm{z}}+\frac{\mathrm{z}}{2}\right) \times \tan \left(\alpha_{\mathrm{hx}}\right) /(\mathrm{R}) \\
& \beta(\mathrm{i}, \mathrm{j}, \mathrm{k})=\theta(\mathrm{j})+(\mathrm{nf}-\mathrm{k}+1) \gamma-\left((\mathrm{i}-1) \mathrm{D}_{\mathrm{z}}+\frac{\mathrm{D}_{\mathrm{z}}}{2}\right) \times \tan \left(\alpha_{\mathrm{hx}}\right) /(\mathrm{R})
\end{aligned}
$$

\subsection{Model Verification and Simulation}

Four different machining test cases were selected from Kline [5] as the basis to test and verify the validity of the extended cutting force model. It was found that the results were in high agreement with Kline's models. The following machining parameters are used for the verification of the case shown in Fig. 4: axial depth of cut 0.5 inches, radial depth of cut 0.4 inches, tool diameter 1 inch, feed 40 inches/min, RPM 400, 4 flutes, helix angle $30^{\circ}$, and the workpiece material was Aluminium 7075. Fig. 4 a shows the cutting force $\left(F_{x}, F_{y}\right)$ when the feed vector is in the direction of positive $\mathrm{x}$ and the cross feed vector is in the positive $\mathrm{y}$ directions. Fig. $4 \mathrm{~b}$ describes the case where the feed vector is in the direction of negative $\mathrm{x}$.
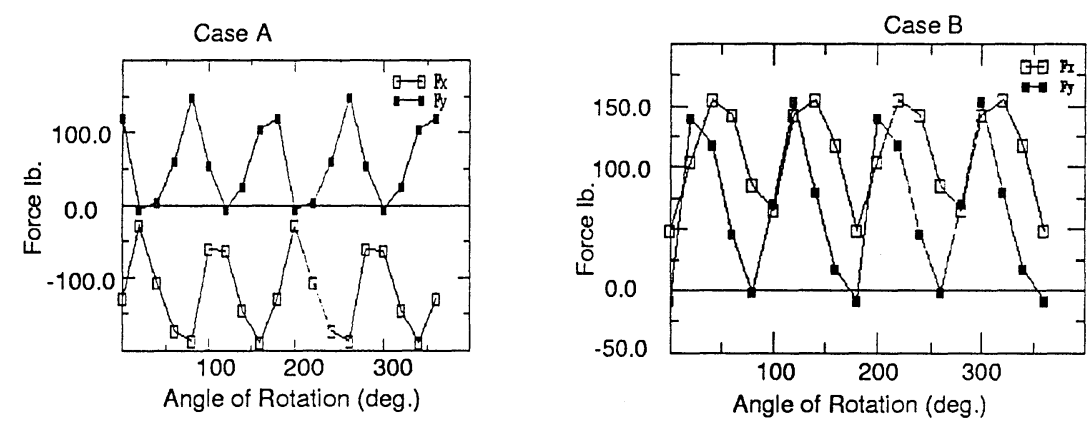

Fig. 4 Simulation of the Extended Cutting Force Model

\section{INTEGRATION ISSUES}

To integrate the cutting force model and the geometric model of the sculptured surface, the following technique has been followed. The surface patch is intersected by parallel planes. This approach guarantees the uniformity of certain process parameters such as: radial depth of cut, and entry and exit angles. The basic element in compensating for the errors due to the cutting force is to calculate the deflection of the end mill. The tool deflection was considered as a simply supported beam and the peak value of the cutting force was used (the maximum value of discrete values calculated for one complete revolution). 


\subsection{Error Compensation}

The deflection of the end mill (error) is calculated at a discrete number of locations over the entire surface patch. An inverse operator is applied to the direction of the tool deflection to calculate an error vector at each point (equation 15). The surface patch is then offset in the direction of the error vector using an offset technique developed by the authors $[8,13]$. Fig. 6 shows a schematic diagram of the compensation algorithm.

$$
\mathrm{d}=\left[\begin{array}{lll}
\Delta x & \Delta y & \Delta z
\end{array}\right]\left[\begin{array}{ccc}
-1 & 0 & 0 \\
0 & -1 & 0 \\
0 & 0 & -1
\end{array}\right] \leadsto \text { Inverse operator }
$$

Where $\overline{\mathrm{d}}$ is the offset vector, $\Delta \mathrm{x}$ is the deflection of the cutting tool due to the cutting force component in the $\mathrm{x}$ direction, $\Delta \mathrm{y}$ is the deflection of the cutting tool due to the cutting force component in the y direction, and $\Delta \mathrm{z}$ was set to zero.

Control Polygon
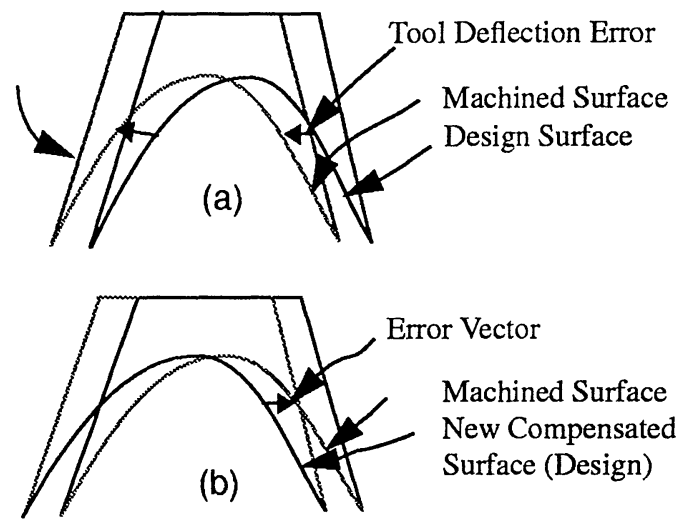

Fig. 6 Schematic Diagram of the Compensation Scheme

\subsection{Model Simulation}

Fig. 7 shows the idea of the surface compensation technique. Machining conditions were: feed rate 20 inches/min, RPM 2000, 4 flutes, helix angle $30 \mathrm{deg}$., workpiece material Aluminum 7075, width of cut 0.04 inches, and tool diameter 0.5 inches.
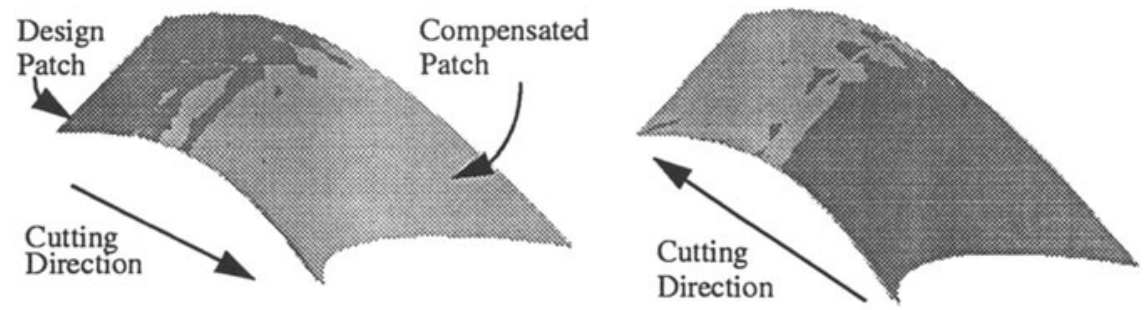

Fig. 7 Simulation of the Design and the Compensated Surfaces 


\section{EXPERIMENTAL RESULTS}

Figures 8 and 9 show two surface patches (surfaces $I$ and II) that were used to test the proposed algorithm. Fig. 8 shows the error whiskers of surface I before and after compensation which indicates an improvement in the surface accuracy of up to 20 percent. Figure 9 shows the shaded image of surface II before and after compensation. The light region has increased (which indicates more region is within the prescribed tolerance). It also shows that the darkness of some regions has decreased, which indicates an improvement in the surface accuracy. Figure 10 shows the design and the compensated surface patches (surface II) during inspection on the CMM. During the inspection the design surface was used to drive the inspection process for both patches. It is believed that incorporating more process parameters, such as initial tool wear, machining with the bottom of an end mill, tool runout, and fixture errors will at least double this percentage. Other sources of error, such as setup errors and fixture errors, can also contribute to this accuracy gain if accurately modelled and predicted. Machine tool errors such as quasi static errors and control system errors are also of high interest for inclusion.

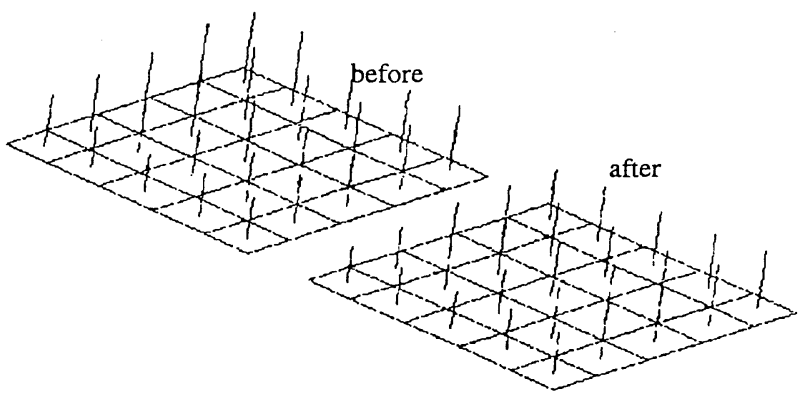

Fig. 8 Surface I Before and After Compensation
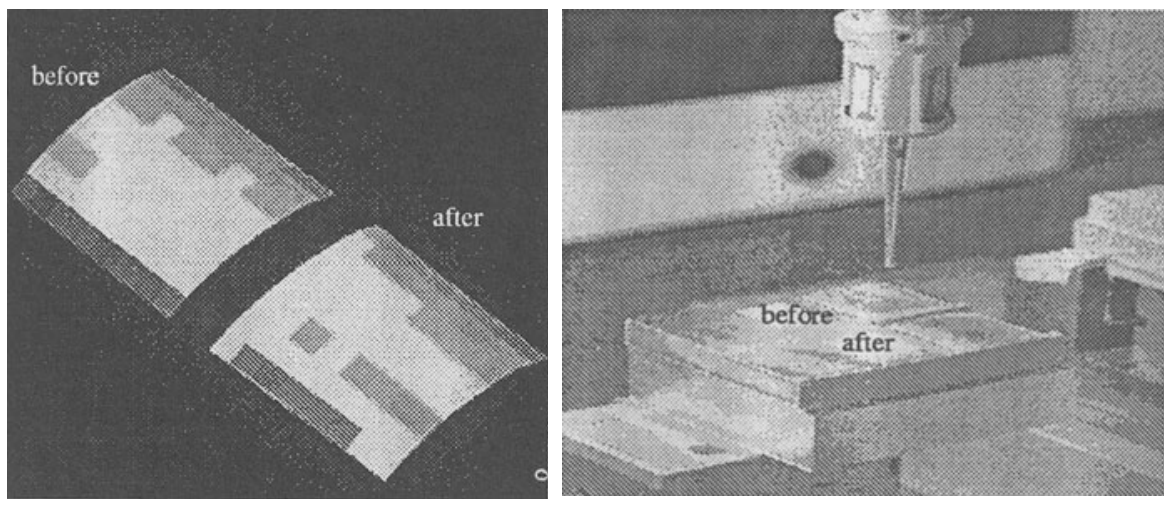

Fig. 9 Surface II before and after

Fig. 10 Surface II During Measurement Compensation 


\subsection{Effect of the Scallop Height on the Accuracy of Inspection}

Lim [15] mentioned that the effect of scallop height on the measurement error ranges from 0 to a maximum height $h$, where $h$ is the scallop height given by equation 16 .

$$
2 h=R-\sqrt{R^{2}-\left(\frac{C}{2 \cos \alpha}\right)^{2}}
$$

where $\mathrm{C}$ is the step over distance, $\mathrm{R}$ is the tool radius, $\alpha$ is the inclination of the of stepover vector. To take the extreme case, two flat surfaces were machined using a ball end mill. The first surface was hand finished to remove the scallops and the other left as is. Using a $12 \mathrm{~mm}$ ball mill tool and a step over distance of $1.8 \mathrm{~mm}, \alpha$ equal to zero. According to equation 16 the scallop height is estimated to be 55 micron. Figure 11 shows the two surfaces after inspection. Excluding the areas near the edges, the inspection error is between (0 to 5\%). This proved that the manual process to remove the scallops did not affect the accuracy of the inspection process.

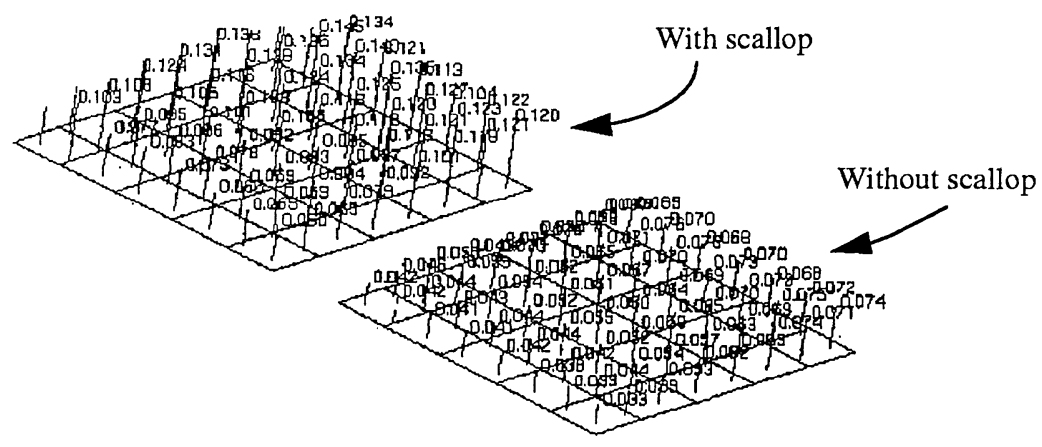

Fig. 11 Effect of the Scallop height on the Measuring Accuracy

\subsection{CONCLUSION}

To compensate for the machining errors during production, a prediction model for the process errors is necessary. In this work a model for the cutting force was used to predict the tool deflection during cutting. An inverse operator was used to calculate the compensation error vector. An offset surface model, developed in previous work, was used to offset the surface in the direction of the error vector.

The results of the simulated design and compensated surfaces, as well as the experimental work performed showed that a geometric model of the compensated surface can be obtained. This may further advance the trend to machine sculptured surfaces with improved accuracy using the existing CAD/CAM systems. 


\section{REFERENCE}

1. Feng, H. Y., Menq, C. H., 1994, "The Prediction of Cutting Forces in the Ball-End Milling Process-1 Model Formulation and Model Building Procedure", Int. J. Mach. Tools Manufact. Vol. 34. No. 5, pp. 697-710.

2. Fussell, B. K., Ersoy, C., Jerard, R. B., 1992, "Computer Generated CNC Machining Feed rates", Japan/USA Symposium on Flexible Automation, Volume 1, pp. 377-384.

3. Yang, B. D., Menq, C. H., 1992, "Compensation for Form Error of End-Milled Sculptured Surfaces Using Discrete Measurement Data", JAPAN/USA symposium on Flexible Automation, Vol. 1 pp. 385-392.

4. Smith, S., Tlusty, J., 1991, "An Overview of Modeling and Simulation of the Milling Process" Journal of Engineering for Industry, May, Vol. 113, pp. 169-175.

5. Kline, W., 1982," The Predication of the Cutting Forces and Surface Accuracy for the End Milling Process", Ph. D thesis, University of Illinois at Urbana-Champaign.

6. Sagherian, R., Elbestawi, M. A., 1990, "A Simulation System for Improving Machining Accuracy in Milling", Computer in Industry, Vol. 14, pp. 293-305.

7. Fujii, Y., Iwabe, H., Suzuki, M.,1979, "Effect of Dynamic Behavior of End Milling in Machining on Work Accuracy (1st Report) - Mechanism of Generating Shape Errors", Bull. Japan Soc. of Prec. Engg., Vol. 13 No.1, pp. 20-26.

8. Gadalla, M. A., ElMaraghy, W. H., 1997, "Improving the Accuracy of Machined Parametric Surfaces Using Cutting Force Synthesis and Surface Offset Techniques", MedVol. 6-1, Manufacturing Science and Technology, Volume 1, ASME 1997, pp. 181-187.

9. Martellotti, M. E., 1941, "An Analysis Of The Milling Process,", Trans. ASME, Vol. 63, pp. 677-700.

10. Martellotti, M. E., 1945,"Analysis Of The Milling Process, Part Ii- Down Milling", Trans. ASME, Vol. 74, pp. 233-251.

11. Hoschek, J., Lasser, D., 1993," Fundamentals of Computer Aided Geometric Design", Wellesley, Massachusetts, A k Peters, Ltd.

12. Farin, G., 1990, "Curves and Surfaces for Computer Aided Geometric Design A practical Guide", Academic Press, Inc. Harcout Brace Jovich, Publishers.

13. Gadalla, M. A., ElMaraghy, W. H., 1998, "Parametric Surface Offsetting Using Surface Subdivision With Application to Free Form Surface Machining and Accuracy Improvement", International Journal for Manufacturing Science and Production, Vol 2.

14. El-Mounayri H. A., Imani, B. M., Elbestawi, M. A., Spencer, A. D., "Closing the Gap between CAD/CAM and Machining Process Simulations: A generic Solution", MEDVol. 6-2, Manufacturing Science and Technology, ASME 1997, pp. 127-134.

15. Lim, Ee Meng, 1995, "The Predication of Dimensional Errors and Machining Planning for Sculptures Surface Productions. Using Ball-End Milling", Ph. D., Thesis, Ohio state University.

16. Fussell B. K., Jerard R. B., Durdag, O.K., 1995, "Geometric And Mechanistic Model Integration for 3-Axis CNC Feedrate Generation", MED-Vol. 1/DE-Vol. 85, Concurrent Product and Process Engineering, pp. 37-51.

17. Hemmett, J. G., Fussell, B. K., Jerard, R. B., 1998, "Automatic 5-axis CNC Feedrate selection via Discrete Mechanistic and Model Integration", Med-Vol. 6-1, Manufacturing Science and Technology Volume 1, ASME 1997, pp. 173-179. 